\title{
The Characteristics of Bulgarian Reward-Based Crowdfunding Campaigns
}

\author{
Assist. Prof. PhD Nevena Dobreva \\ Varna University of Management, Varna, Bulgaria \\ nevena.dobreva@vumk.eu
}

\begin{abstract}
Reward-based crowdfunding is the most popular method for acquiring financial resources directly from potential users. Bulgarian entrepreneurs and small companies have the opportunity to search for funding from international online communities that are active in the biggest reward-based crowdfunding platforms as Kickstarter and Indiegogo. The proposed paper aims to examine the current state and characteristics of the Bulgarian campaigns in Kickstarter, to identify success factors for generating funds and give directions for better performance of Bulgarian entrepreneurs in reward-based crowdfunding.
\end{abstract}

Keywords: reward-based crowdfunding, crowdfunding campaigns, incentives, rewards

JEL Code: O33; doi:10.36997/IJUSV-ESS/2019.8.1.174

\section{Introduction ${ }^{1}$}

Crowdfunding is a new financial mechanism for acquiring funds directly from the potential users and consumers. Many entrepreneurs and small companies launch their innovative and risky projects in the crowdfunding platforms not only for receiving financial contributions, but to build their audience in advance, bypass traditional funding mechanisms and develop their products in line with the needs and recommendations of consumers. Bulgarian entrepreneurs are also represented in the crowdfunding platforms that enable them to easily enter the international scene and realise their products on the global market. This paper aims to explore the current state and characteristics of Bulgarian campaigns in the largest reward-based crowdfunding platform Kickstarter and to identify factors for their success.

\section{Characteristics of reward-based crowdfunding}

The emergence and evolvement of crowdfunding is closely related to web 2.0 applications that enable interactions between entrepreneurs and their potential users and consumers in the virtual space. Belleflamme, Lambert and Schwienbacher (2014) propose one of the most inclusive definitions of this activity: 'Crowdfunding involves an open call, mostly through the Internet, for the provision of financial resources either in the form of donation or in exchange for the future product or some form of reward to support initiatives for specific purposes' (Belleflamme et al., 2014: 588). In relation to the characteristics of the campaigns, the forms of contributions and the relationships between entrepreneurs and their supporters, at least five basic models of crowdfunding can be identified - donations, reward-based, pre-sale, lending, and investment model.

In the case of reward-based crowdfunding, in exchange for financial contributions, the entrepreneur gives to supporters tangible and intangible gifts to show his appreciation. This feature makes reward-based crowdfunding one of the most popular models, especially for entrepreneurs in cultural and creative industries who can deliver a number of derived products from their initial idea. Only partially reward-based crowdfunding overlaps e-commerce business model, because the product does not exist prior to the campaign and supporters are differently motivated than those in e-commerce (Beaulieu, Sarker and Sarker, 2015). In this view, reward-based crowdfunding can be

\footnotetext{
1 Acknowledgement: This publication is developed within the frame of Project BG05M2OP001-1.002-0008-C01 "Centre for Competence and Intelligent Solutions for the Creative and Recreational Industries" (INCREA). The project has been funded within Operational Programme "Science and Education for Smart Growth (2014-2020)" and with support from the European Union. The publication reflects the views only of the author and the European Union cannot be held responsible for any use, which may be made of the information contained therein.
} 
considered as a sub-model of donation crowdfunding, because supporters are primary interested in helping the entrepreneur than just in collecting the reward.

Entrepreneurs start their campaigns in crowdfunding platforms by setting a funding goal and describing the project idea. They typically add visual materials as photos and videos of the prototype, creative process and the team, and design the reward tier. The launched campaign can be linked to social networks, which allows forming a networked effect and reaching more potential supporters. The campaign is online for a fix period and afterwards depending on the payoff mode set by the platform, the money raised can be paid to the entrepreneur. The most popular modes in reward-based crowdfunding are all-or-nothing - the financial contributions are released to the entrepreneur only if the funding goal is reached, and the keep-what-you-raise model - the entrepreneur can keep the money regardless of whether the funding goal is achieved or not (Tomszak and Bren, 2013). In Kickstarter, the used payoff mode is all-or-nothing, which is more convenient for supporters who will receive their contributions back if the campaign fails. On the other hand, this mode makes entrepreneurs more careful in determining their funding targets.

Many scholars focus on identifying the most influential success factors in reward-based crowdfunding. These determinants are related to project description, design and number of rewards, duration of the campaign, audio-visual presentation, funding goal, active engagement of supporters, etc. Regarding the project description, entrepreneurs have to provide a well-made project homepage and a video card in order to present their ideas fully. Extensive descriptions have a positive effect only if they are consistent (Kunz, Bretschneider, Erler and Leimeister, 2017; Barbi and Bigelli, 2017), not chaotic showing the entrepreneur' inability to focus on his own ideas. Researchers also emphasise the duration of the campaign, finding that a longer funding period has a negative impact on the success of the project (Kunz et al., 2017, Barbi and Bigelli, 2017, Bilau and Pires, 2018, Janků and Kučerová, 2018). While Bœuf, Darveau, and Legoux (2014) offer as an optimal period of 40 to 60 days, Cox and Nguyen (2018) even suggest a shorter period of 30 days. Janků and Kučerová (2018) also reveal empirically that entrepreneurs should launch their projects during workdays when supporters dedicate more time to web activities compared to the weekends.

Other influential factors for the success of campaigns are the design of rewards and the funding goal. Researchers express different opinions about the number and the design of reward tier. The higher price of the top reward items gives an encouraging signal about the quality of the project (Xiao, Tan, Dong and Qi, 2014), while the number of options is positively correlated with the average price of options of reward tier (Du and Wang, 2017). Symbolic rewards are a strong motivating factor for some supporters, especially in art projects (Bœuf et al., 2014) where prosocial behaviour is observed, and material rewards can have the opposite effect. The higher number of different rewards increases the likelihood of success, thus Kunz, Englisch, Beck and Bretschneider (2016) suggest that entrepreneurs can offer a variety of rewards, but not implementing too many price categories.

Scholars agree that higher funding goals lower the probability of success (Šoltés and Štofa, 2016, Barbi and Bigelli, 2017, Cox and Nguyen, 2018, Ferreira and Pereira, 2018). Entrepreneurs can raise more money with a higher funding target, but the likelihood of achieving that goal declines. Therefore, realistic funding goals, which correspond with the type of the project, are important indicators of campaign success.

In the crowdfunding platforms, active communication and regular updates are key aspects of engaging supporters. Entrepreneurs enhance supporters' investments by more published updates and by increasing the number of answered questions (Kunz et al, 2017). On the other hand, the number of comments left by supporters indicates for the success of a campaign (Petitjean, 2018). Social networks further influence the supporters' decision to invest in a particular project.

Another phenomenon observed in crowdfunding is the potential fatigue (Bœuf et al., 2014), when an entrepreneur has previously launched several campaigns. In that situation, not the average amount pledged decreases but the number of supporters. The platform itself can influence the 
supporters' decisions (Koch, 2016). For instance, the Kickstarter team gives the label 'Project we love' to creative and well-planned campaigns. The label immediately provides a positive signal to potential supporters.

Well-prepared campaigns rise the probability of success, but there is no single formula for attracting supporters. Entrepreneurs all over the world come together to the crowdfunding platforms not to compete with each other, but to present their ideas and ask for support from diverse audiences and users. The crowd does not automatically give away money for interesting and well-presented projects; their wisdom can gauge the potential of ideas and products in the crowdfunding platforms. Bulgarian entrepreneurs have equal chances to present their ideas, gain financial contributions, build their audiences in advance and realise their products on the international market.

\section{Overview of the Bulgarian reward-based crowdfunding campaigns in Kickstarter}

The empirical research conducted in the period September - October 2019 includes a sample of 112 campaigns, which allows to be identified the main characteristics and success factors of Bulgarian reward-based crowdfunding campaigns. The study is limited to campaigns launched in one of the most popular reward-based crowdfunding platforms - Kickstarter.

In the period June 2011 - October 2019, 92 Bulgarian entrepreneurs and creative teams launched 112 reward-based crowdfunding campaigns in Kickstarter. The success rate of these projects is $30.36 \%$ (34 campaigns), which is lower than the average of $37.34 \%^{2}$ for the platform. While $78 \%$ of all campaigns in the platform that raised more than $20 \%$ of their goal were successfully funded, the same percentage of the Bulgarian projects is considerably lower $-65.38 \%$. On the contrary, $32.14 \%$ of the Bulgarian campaigns have attracted not more than 5 supporters (as 4 campaigns received no contribution). In terms of geographic distribution, 77 out of 112 projects were launched from Sofia and the rest originate from 20 different Bulgarian cities. There is no significant difference in the success rate of the projects released from the capital $(31.17 \%)$, compared to those from other cities $(28.57 \%)$.

During the examined period, Bulgarian entrepreneurs and creative teams launched campaigns in every product category except Journalism. The distribution of the projects through categories shows that the most popular ones are Games (25.89\%), Design (13.39\%), Film \& Video $(10.71 \%)$ and Technology (10.71\%) (Fig. 1). Not surprisingly, most of the successful campaigns belong to the Games category, as 8 projects are in the Tabletop games sub-category, 2 in Playing cards and 2 in Video games. In general, entrepreneurs and creative teams from product design and game industries are more willing to start a reward-based crowdfunding campaign for fundraising and testing the market interest and relevance of their products.

Bulgarian entrepreneurs tried to raise more than 2.6 million USD, while successful campaigns gained approx. 572 thousand USD from 25373 supporters. The average funding goal of successful projects is approx. 16831 USD, which is almost twice lower compared to the projects, which were cancelled or failed to reach their goal. This shows that a better strategy is setting of a realistic fundraising goal for acquiring the needed funds. Supporters may continue pledging for projects even if the goal has already been achieved. This is encouraging for entrepreneurs, as two projects received more than $1500 \%$ of their funding goals - Halfbike II $^{3}$ (reached 1947.53\%) and Folded Space - Board Game Inserts Campaign $3^{4}$ (reached 1644.47\%). Even though the average amount pledged is lower for the successful projects, the number of supporters can be many times

\footnotetext{
${ }^{2}$ Data retrieved from official Kickstarter website (https://www.kickstarter.com/help/stats) on 21.11.2019.

${ }^{3}$ Halfbike II project was launched by Kolelinia on 7 April 2015 and reached 973764 USD from 2416 supporters, while the funded target was 50000 USD. Link to the campaign: https://www.kickstarter.com/projects/halfbike/halfbike-ii [Last Accessed on 25 October 2019].

${ }^{4}$ Folded Space - Board Game Inserts Campaign 3 project was launched by Folded Space on 15 December 2018 and reached 210925 USD from 4366 supporters, while the funded target was 12900 USD. Link to the campaign: https://www.kickstarter.com/projects/265550568/folded-space-board-game-inserts-campaign-3 [Last Accessed on 25 October 2019].
} 
higher as seven campaigns have managed to attract between 1000 and 5000 supporters.

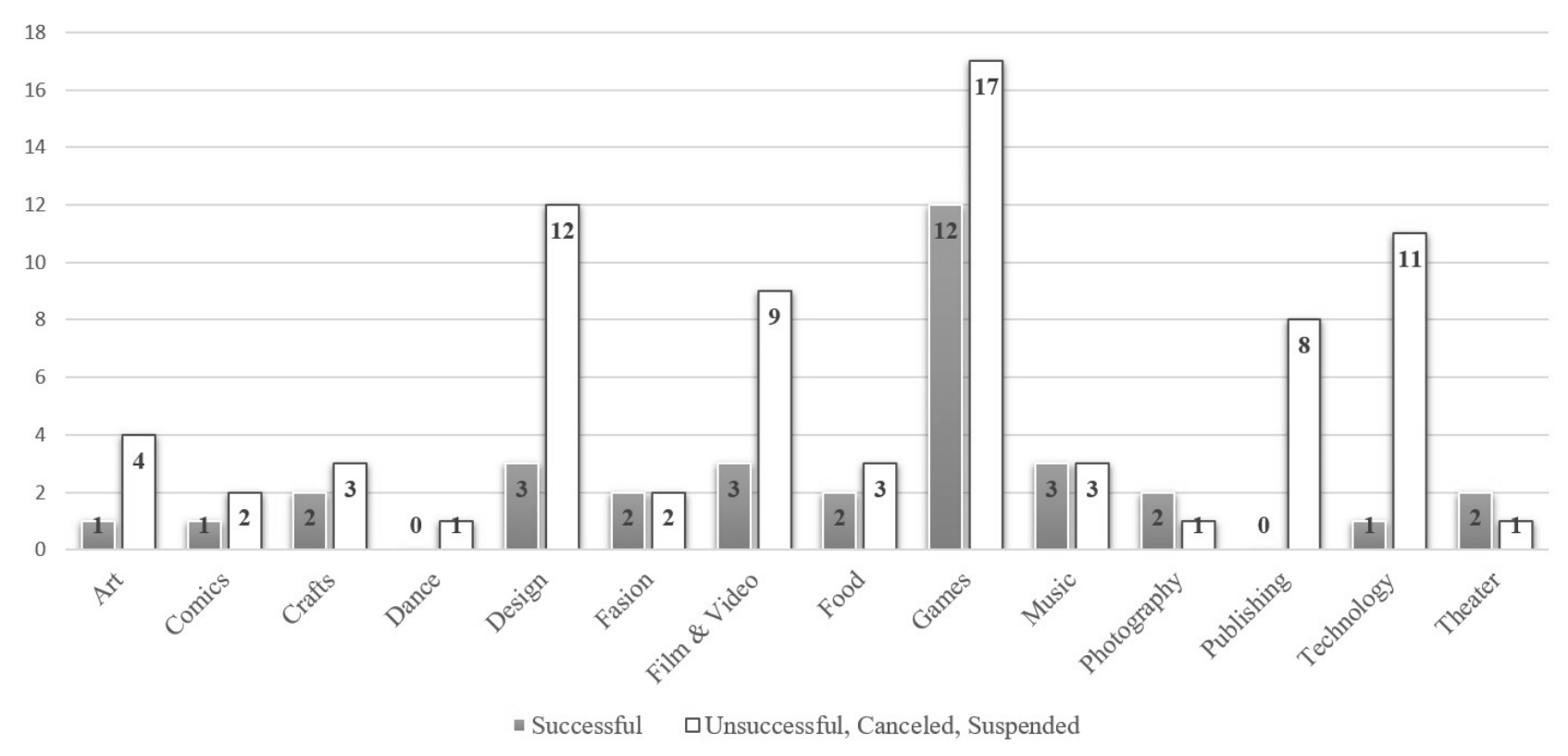

Figure 1. Distribution of crowdfunding projects according to their status and category.

In some cases, entrepreneurs decide not to wait until the end of the funding period to cease their campaigns ( $16.07 \%$ or 18 projects were cancelled by their creators). They usually notify the supporters for their reasons and future plans regarding the projects. The entrepreneurs' motivations to cancel their campaigns are manifold, but mainly because of unrealistic funding goals that cannot be achieved during the funding period or the lack of interest to the project. Some of these entrepreneurs share in the platform that they intend to analyse their mistakes and relaunch the campaigns, find new opportunities for funding as an alternative to crowdfunding, or realise the product without additional funding (especially for video games). Six entrepreneurs relaunched their campaigns and as a result, four of these projects were successfully funded.

The campaigns usually last 30 days (50\% of all Bulgarian campaigns). However, $1 / 3$ of the campaigns have a longer funding period and the success rate for these projects is $20 \%$. If the campaign is well prepared and the entrepreneur is confident in his idea, a shorter funding period may create a positive signal to supporters. For instance, the shortest period of a campaign in the sample is one week, during which the entrepreneur gained twice-higher funds than his initial goal

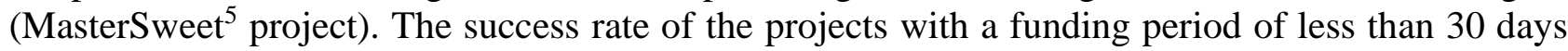
is significantly higher $(42.86 \%)$.

The distribution of the projects according to the released day, week and year (Table 1) shows that Bulgarian entrepreneurs prefer to launch their projects during the workdays, as the highest success rate is for campaigns launched on Monday, followed by those realised on Thursday and Tuesday. Regarding the months of the year, the biggest number of campaigns launched is in June, followed by April and July. Accordingly, the most unpopular months are February, May and August, where the number of successful projects is also low. The most active year for Bulgarian entrepreneurs was 2015 when they launched 23 projects and nine of them were successfully funded. In the last three years, Bulgarian entrepreneurs do not use Kickstarter so intensively, but the success rate retains its level of $30 \%$.

\footnotetext{
${ }^{5}$ MasterSweet project was launched by Board Games Yunak on 12 December 2018 and reached 1483 USD from 50 supporters, while the funded target was 750 USD. Link to the campaign: https://www.kickstarter.com/projects/446077073/mastersweets [Last Accessed on 25 October 2019].
} 
Table 1. Distribution of the projects according to released day of the week, month of the year and year.

\begin{tabular}{|c|c|c|c|c|c|c|c|}
\hline & \multicolumn{5}{|c|}{ Status of the campaigns } & \multirow[t]{2}{*}{ Total } \\
\hline & & Total & Successful & Unsuccessful & Cancelled & Suspended & \\
\hline \multicolumn{2}{|c|}{$\begin{array}{l}\text { Number of the campaigns } \\
\text { according to their status }\end{array}$} & 112 & 34 & 59 & 18 & 1 & $100 \%$ \\
\hline \multirow{7}{*}{$\begin{array}{l}\text { Released } \\
\text { day of the } \\
\text { week }\end{array}$} & Monday & 17 & 8 & 6 & 3 & 0 & $15.18 \%$ \\
\hline & Tuesday & 21 & 7 & 7 & 7 & 0 & $18.75 \%$ \\
\hline & Wednesday & 18 & 4 & 12 & 2 & 0 & $16.07 \%$ \\
\hline & Thursday & 21 & 8 & 10 & 2 & 1 & $18.75 \%$ \\
\hline & Friday & 23 & 4 & 15 & 4 & 0 & $20.54 \%$ \\
\hline & Saturday & 8 & 1 & 7 & 0 & 0 & $7.14 \%$ \\
\hline & Sunday & 4 & 2 & 2 & 0 & 0 & $3.57 \%$ \\
\hline \multirow{12}{*}{$\begin{array}{l}\text { Released } \\
\text { month of } \\
\text { the year }\end{array}$} & January & 8 & 3 & 5 & 0 & 0 & $7.14 \%$ \\
\hline & February & 4 & 1 & 2 & 1 & 0 & $3.57 \%$ \\
\hline & March & 7 & 3 & 3 & 1 & 0 & $6.25 \%$ \\
\hline & April & 14 & 3 & 8 & 3 & 0 & $12.5 \%$ \\
\hline & May & 5 & 0 & 1 & 3 & 1 & $4.46 \%$ \\
\hline & June & 17 & 5 & 9 & 3 & 0 & $15.18 \%$ \\
\hline & July & 13 & 4 & 7 & 2 & 0 & $11.61 \%$ \\
\hline & August & 5 & 1 & 3 & 1 & 0 & $4.46 \%$ \\
\hline & September & 6 & 3 & 3 & 0 & 0 & $5.36 \%$ \\
\hline & October & 12 & 5 & 5 & 2 & 0 & $10.71 \%$ \\
\hline & November & 12 & 3 & 7 & 2 & 0 & $10.71 \%$ \\
\hline & December & 9 & 3 & 6 & 0 & 0 & $8.04 \%$ \\
\hline \multirow{9}{*}{$\begin{array}{l}\text { Released } \\
\text { year }\end{array}$} & 2011 & 4 & 2 & 2 & 0 & 0 & $3.57 \%$ \\
\hline & 2012 & 5 & 1 & 4 & 0 & 0 & $4.46 \%$ \\
\hline & 2013 & 4 & 2 & 2 & 0 & 0 & $3.57 \%$ \\
\hline & 2014 & 16 & 4 & 11 & 1 & 0 & $14.29 \%$ \\
\hline & 2015 & 23 & 9 & 11 & 2 & 1 & $20.54 \%$ \\
\hline & 2016 & 20 & 4 & 10 & 6 & 0 & $17.86 \%$ \\
\hline & 2017 & 12 & 5 & 6 & 1 & 0 & $10.71 \%$ \\
\hline & 2018 & 16 & 5 & 5 & 6 & 0 & $14.29 \%$ \\
\hline & 2019 & 12 & 2 & 8 & 2 & 0 & $10.71 \%$ \\
\hline
\end{tabular}

All campaigns run by Bulgarian entrepreneurs contain a video message, a description of the idea and a reward tier. In most cases, entrepreneurs add visual materials of the creative process, product prototype and derived products, which can be collected as rewards. The number of rewards varies from 1 to 35 , while the average is 8.38. The design and number of rewards is an essential element influencing the overall performance of a campaign, since for projects that received less than $10 \%$ of their funding goal, the average number of rewards is significantly lower (6.37). Unexpectedly, the average price of the top reward for the successful projects is considerably lower than the average amount for the whole sample. The highest price for a top reward actually pledged for a successful project is approx. 5500 USD. Furthermore, the price of the top reward is lower than 1000 USD for 25 out of 34 successful campaigns, which signals that entrepreneurs should also consider carefully the prices of the different rewards offered.

Entrepreneurs, who succeed in their campaigns, usually present a combination of different types of rewards including presale of the final product (for 21 out of 34 projects), symbolic rewards (for 22 projects), and derived products (for 27 projects). For six successfully funded projects (4 of them in the Games category), the supporters received a discount of the final product equal to the amount pledged. The reward tiers for $82.35 \%$ of the successful campaigns are a mix of two or three types of rewards, including symbolic, pre-sale, derived products, or discount vouchers. It can be concluded that entrepreneurs in cultural and creative industries effectively manage to offer the right blend of symbolic rewards as thank-you cards and including supporters in the credits of the products (even as game characters) and also deliver derived products as t-shirts, posters, toys, etc.

Some entrepreneurs decide to use their previous success to launch similar products for their next campaigns. The phenomenon of fatigue (less supporters compared to the previous campaign) is observed in five cases, while some entrepreneurs (eight cases) manage to use their prior experience to enrich their products and reach even more supporters in their subsequent campaigns. An interesting example is Grozen ENT. Company for comic books, which after failing to meet its 
funding goal, one month later the company launched the same campaign halving its funding goal and doubling the number of rewards, and manage to rise twice as much.

Table 2. Distribution of average number of rewards, backers, pledge amount, campaigns' period, updates and comments according to the projects' status.

\begin{tabular}{|c|c|c|c|c|c|c|c|}
\hline $\begin{array}{c}\text { Average/ Project } \\
\text { status }\end{array}$ & $\begin{array}{c}\text { Number of } \\
\text { rewards }\end{array}$ & $\begin{array}{c}\text { Highest reward } \\
\text { in USD }\end{array}$ & $\begin{array}{c}\text { Number of } \\
\text { Backers }\end{array}$ & $\begin{array}{c}\text { Pledge amount } \\
\text { in USD }\end{array}$ & $\begin{array}{c}\text { Campaign } \\
\text { active days }\end{array}$ & Updates & Comments \\
\hline Total & 8.38 & 1661.43 & 246.6 & 87.81 & 33.79 & 7.4 & 116.35 \\
\hline Successful & 9.35 & 1027.82 & 746.26 & 77.82 & 30.56 & 19.38 & 372.44 \\
\hline Unsuccessful & 7.07 & 1856.61 & 14.54 & 85.99 & 36.36 & 1.19 & 1.32 \\
\hline Canceled & 11.28 & 2316.97 & 77.06 & 117.2 & 31.67 & 5.56 & 16.11 \\
\hline Suspended & 1 & 6.45 & 1 & 6 & 30 & 0 & 0 \\
\hline
\end{tabular}

One of the most important domains, when examining the characteristics of crowdfunding campaigns, is the interaction between entrepreneurs and their supporters. As a mediated environment, the crowdfunding platforms provide several avenues for communicating with users and promoting projects. Entrepreneurs can continually provide updates and respond to users' comments, recommendations and suggestions regarding the development of their products. However, only in 70 campaigns, entrepreneurs provided updates on their activities and 84 projects received comments from supporters. Table 2 shows that the regular updates and comments significantly increase the chances of success. Only one project in the Art category (Up River - A Group Exhibition ${ }^{6}$ ) was successful without adding any updates or receiving any comments from supporters. The project received the largest number of comments (2274) is Halfbike II. The most active entrepreneurs in engaging with their audience and supporters are those who come from the game and product design industries, while the lowest levels of engagement are observed in the Dance, Art and Photography categories.

Table 3. Distribution of appearances in social media, websites and labelling in the platform according to the projects' status.

\begin{tabular}{|c|c|c|c|c|c|c|c|c|c|c|c|c|}
\hline Project status & \multicolumn{2}{|c|}{ Total } & \multicolumn{2}{|c|}{ Website } & \multicolumn{2}{|c|}{ Twitter } & \multicolumn{2}{|c|}{ Facebook } & \multicolumn{2}{|c|}{ YouTube } & \multicolumn{2}{|c|}{ Projects We love } \\
\hline Total & 112 & $100 \%$ & 75 & $66.96 \%$ & 12 & $10.71 \%$ & 31 & $27.68 \%$ & 3 & $2.68 \%$ & 11 & $9.82 \%$ \\
\hline Successful & 34 & $30.36 \%$ & 26 & $76.47 \%$ & 6 & $17.65 \%$ & 14 & $41.18 \%$ & 1 & $2.94 \%$ & 8 & $23.53 \%$ \\
\hline Unsuccessful & 59 & $52.68 \%$ & 35 & $59.32 \%$ & 2 & $3.39 \%$ & 9 & $15.25 \%$ & 2 & $3.39 \%$ & 1 & $1.69 \%$ \\
\hline Cancelled & 18 & $16.07 \%$ & 14 & $77.77 \%$ & 4 & $22.22 \%$ & 8 & $44.44 \%$ & 0 & / & 2 & $11.11 \%$ \\
\hline Suspended & 1 & $0.89 \%$ & 0 & I & 0 & I & 0 & I & 0 & 1 & 0 & l \\
\hline
\end{tabular}

Another way to interact with supporters is though social media. The crowdfunding platforms provide an option for linking the campaign to social networks. However, Bulgarian entrepreneurs do not take enough advantage of the networked effect that social networks can bring, as only $31.25 \%$ of them have used Facebook, Twitter or YouTube to promote their campaigns (Table 3).

${ }^{6}$ Up River - A Group Exhibition was launched by Up River on 15 March 2017 and reached 1374 USD from 18 supporters, while the funded target was 1290 USD. Link to the campaign:

https://www.kickstarter.com/projects/652048913/up-river-a-group-exhibition [Last Accessed on 25 October 2019]. 
The existing of a website for the project or entrepreneur's company has a positive effect on legitimacy of the campaigns and most of the entrepreneurs shared it in the platform as a source of additional information about their portfolio, company or product.

The platform itself can influence the campaigns' performance. It is apparent that the labelling 'Project we love' by the Kickstarter team has a positive effect on the campaigns, as 8 out of 11 projects with that label have been funded. The label is obtained when the campaign is assessed according to the quality of the project description, images or video, a plan for completion, its community and creativity. Table 4 shows that the projects received the label attract more supporters who make larger contributions. The average price of the top award is also greater, which could be a signal for the self-confidence of the entrepreneur. Furthermore, the entrepreneurs' activity and interactions with their audiences is several times higher than the average for the whole sample.

Table 4. Distribution of average number of rewards, backers, the price of the top reward, pledge amount, campaigns' period, updates and comments according to the presence of the label 'Project we love'.

\begin{tabular}{|c|c|c|c|c|c|c|c|}
\hline $\begin{array}{c}\text { Average/ } \\
\text { 'Project we love' label }\end{array}$ & $\begin{array}{c}\text { Number of } \\
\text { rewards }\end{array}$ & $\begin{array}{c}\text { Highest } \\
\text { reward in USD }\end{array}$ & $\begin{array}{c}\text { Number of } \\
\text { Backers }\end{array}$ & $\begin{array}{c}\text { Pledge amount } \\
\text { in USD }\end{array}$ & $\begin{array}{c}\text { Campaign } \\
\text { active days }\end{array}$ & Updates & Comments \\
\hline Total (112 projects) & 8.38 & 1661.43 & 246.6 & 87.81 & 33.79 & 7.4 & 116.35 \\
\hline $\begin{array}{c}\text { Without a label } \\
\text { (101 projects) }\end{array}$ & 7.9 & 1612.83 & 136.48 & 83.78 & 34.01 & 5.51 & 50.01 \\
\hline $\begin{array}{c}\text { With a label } \\
\text { (11 projects) }\end{array}$ & 12.82 & 2107.67 & 1257.73 & 124.85 & 31.73 & 24.73 & 725.45 \\
\hline
\end{tabular}

The examined campaigns of Bulgarian entrepreneurs and creative teams in Kickstarter show that reward-based crowdfunding can be a fruitful tool for attracting funds for innovative and risky projects, especially in cultural and creative industries. Bulgarian entrepreneurs manage to offer interesting campaigns and attract thousands of supporters. However, the overall success rate reminds under the average for Kickstarter. The main problem areas of Bulgarian campaigns are setting of unrealistically high funding goals, inability to engage potential supporters in the development of the products, the lack of interactions with supporters through the platform and social networks. On the other hand, Bulgarian entrepreneurs learn from their mistakes and succeed in improving their campaigns to be entirely funded or replicate the previous success into new campaigns to hold the attention of created audiences and users.

\section{Success factors for generating funds for Bulgarian reward-based crowdfunding campaigns in Kickstarter}

It is apparent that Bulgarian entrepreneurs in cultural and creative industries more often use crowdfunding for acquiring financial resources directly from their future users and consumers. They also benefit from the advantages that crowdfunding brings beyond fundraising as safeguarding creative independence and organisational ownership, building and engaging potential audiences, innovating business models and restructuring value chains (Dobreva, 2019). If we look up in the successful projects, 6 out of 34 are built on previous successful campaigns in the platform. Thus, Bulgarian entrepreneurs manage to use the crowdfunding platform also as a market place for their products, which allows them easily to access international audiences and consumers.

Creativity and intensive interactions with the crowd are in the centre of successful campaigns in reward-based crowdfunding. However, it is possible to be outlined some factors, which can enhance the probability of success. The well-design reward tier, which is composed of both symbolic and material rewards (including discounts or pre-sale of the final product), can attract 
diverse groups of supporters. Hence, entrepreneurs need to dedicate time in building the reward tier in such a way to address different motivational factors of potential supporters. The higher price of the top reward does not influence the likelihood of success in the given sample; even it is advisory entrepreneurs to keep the price of the top reward lower than the average of 1661 USD for all campaigns.

Setting the funding goal is another crucial factor of success, especially in a platform using all-or-nothing payment mode. The funding goal should correspond to the real costs for creating the products; the higher goals can repel the crowd. On the other hand, most of the successful projects acquire more than twice the funding targets, which additionally guarantee the quality of the projects and building on legitimacy of the entrepreneurial endeavour.

The campaigns' period does not have significant influence on the probability of success in the given sample, in which the funding period does not exceed 60 days. However, the shorter funding period is a signal to supporters that the entrepreneur is confident in the campaign and the quality of the proposed product. Launching the campaigns on weekdays and in months when potential supporters are usually not on vacation and not participating in web activities is a possible strategy for Bulgarian entrepreneur and creative teams.

The regular updates and answering questions is a way for interaction between the entrepreneur and his supporters. The entrepreneur's activity can be a signal for potential supporters who need more persuasion to invest in a specific campaign. Hence, as a way for gaining additional legitimacy for the entrepreneurial endeavour, the entrepreneur should be an active agent in the platform during the whole period of the campaign. The entrepreneur's website and profiles in social networks can also facilitate the engagement of potential supporters. The phenomenon of fatigue is also observed when entrepreneurs just replicate previous campaigns without innovating their products or updating the reward tier. In brief, sufficient time for preparation is needed for building a successful campaign that will attract and engage the crowd.

\section{Conclusion}

Bulgarian entrepreneurs and creative teams do use crowdfunding platforms to receive financial contributions from diverse groups of users and audiences. The considered sample of campaigns shows that Bulgarian entrepreneurs learn from their mistakes, dedicate time to compose attractive reward tiers and succeed to replicate their previous success. On the other hand, very often they set unrealistic funding goals, do not interact enough with their supporters in the platform and do not benefit from social networks as a way to engage more supporters who are not usually active in crowdfunding platforms. The identified success factors confirm the findings of other studies on reward-based crowdfunding. The probability of success increases when entrepreneurs take the time to build the reward tier, set adequate funding goal, be active in answering questions, keep the audience updated on product development, and consider a shorter campaign period. Future research on reward-based crowdfunding may consider the various motives for starting crowdfunding campaigns and analyse the post-campaign performance of entrepreneurs. Researchers can also explore and compare the characteristics of Bulgarian campaigns in other reward-based crowdfunding campaigns.

\section{References}

1. Barbi, M. and Bigelli, M. (2017) Crowdfunding Practices in and outside the US. Research in International Business and Finance. 42. pp. 208-223.

2. Beaulieu, T., Sarker, S. and Sarker, S. (2015) A Conceptual Framework for Understanding Crowdfunding. Communications of the Association for Information Systems. 37. pp. 1-30.

3. Belleflamme, P., Lambert, T. and Schwienbacher, A. (2014) Crowdfunding: Tapping the Right Crowd. Journal of Business Venturing. 29(5). pp. 585-609. 
4. Bilau, J. and Pires, J. (2018) What is the Role of Networks and Geography in Reward-based Crowdfunding Success? Proceedings of the European Conference on Innovation and Entrepreneurship, ECIE. University of Aveiro, 20-21 September. Aveiro: Universidade de Aveiro. pp. 102-111.

5. Bœuf, B., Darveau, J. and Legoux, R. (2014) Financing Creativity: Crowdfunding as a New Approach for Theatre Projects. International Journal of Arts Management. 16(3). pp. 33-48.

6. Cox, J. and Nguyen, T. (2018) Does the Crowd Mean Business? An Analysis of Reward-based Crowdfunding as a Source of Finance for Start-ups and Small Businesses. Journal of Small Business and Enterprise Development. 25(1). pp. 147-162.

7. Du, Z. and Wang, K. (2017) More Options Make Crowdfunding Campaigns More Successful? Investigation of the Underlying Mechanism. AMCIS 2017 - America's Conference on Information Systems: A Tradition of Innovation. 10-12 August. Boston: Association for Information Systems.

8. Dobreva, N. (2019). Advantages of Reward-based Crowdfunding for Cultural and Creative Industries. Yearbook of Varna University of Management. Vol. XII. pp. 296-304.

9. Ferreira, F. and Pereira, L. (2018) Success Factors in a Reward and Equity Based Crowdfunding Campaign. 2018 IEEE International Conference on Engineering, Technology and Innovation (ICE/ITMC). 17 June. Baden-Wuerttemberg: IEEE.

10. Janků J. and Kučerová Z. (2018) Successful Crowdfunding Campaigns: The Role of Project Specifics, Competition and Founders' Experience. Finance a Uver - Czech Journal of Economics and Finance. 68(4). pp. 351-373.

11. Koch, J. (2016) The Phenomenon of Project Overfunding on Online Crowdfunding Platforms Analyzing the Drivers of Overfunding. 24th European Conference on Information Systems, ECIS 2016. 12-15 June. Istanbul.

12. Kunz, M., Bretschneider, U., Erler, M. and Leimeister, J. (2017) An Empirical Investigation of Signaling in Reward-based Crowdfunding. Electronic Commerce Research. 17(3). pp. 425-461.

13. Kunz, M., Englisch, O., Beck, J. and Bretschneider, U. (2016) Sometimes You Win, Sometimes You Learn - Success Factors in Reward-based Crowdfunding. Multikonferenz Wirtschaftsinformatik, MKWI 2016, Technische Universität Ilmenau. 9-11 March. Ilmenau. 1. pp. 467-478.

14. Petitjean, M. (2018) What Explains the Success of Reward-based Crowdfunding Campaigns as They Unfold? Evidence from the French Crowdfunding Platform KissKissBankBank. Finance Research Letters. 26. pp. 9-14.

15. Šoltés M. and Štofa T. (2016) Crowdfunding - The Case of Slovakia and the Czech Republic. Quality Innovation Prosperity. 20(2). pp. 89-104.

16. Tomszak, A. and Bren, A. (2013) A Conceptualized Investment Model of Crowdfunding. Venture Capital. 15(4). pp. 335-359.

17. Xiao, S., Tan, X., Dong, M. and Qi, J. (2014) How to Design your Project in the Online Crowdfunding Market? Evidence from Kickstarter. $35^{\text {th }}$ International Conference on Information Systems (ICIS). 14-17 December. Auckland: Association for Information Systems. 